\title{
Increased Dependence on Visual Information for Movement Control in Patients with Parkinson's disease
}

\author{
J.D.COOKE, J.D.BROWN AND V.B.BROOKS
}

SUMMARY: Studies were made of visualIy and non-visually guided movements by patients with Parkinson's disease. The subjects moved a light, horizontal handle using rotation primarily about the elbow. During visually guided trials both handle and target positions were displayed to the subject; during non-visually guided trials only the handle position was displayed. During non-visually guided trials all patients showed a tendency for an overall

RESUME: Les mouyements guidés ou non visuellement furent éludiés chez des patients avec maladie de Parkinson. Les sujets doivent bouger une poignée légèe, horizontale, en emplolant surtout une rotation au niveau du coude. Lors des essais guidés visuellement les positions de la poignée et de la cible sont illustrés pour le sujet; lors des essais non guidés visuellement seule la position de la poignée est illustrée. Lors des essais non guidés visuellement tous les patients ont montré une tendance à la

From the Departments of Physiology and Clinical Neurological Sciences. University of Western Ontario, London, Canada.

Reprint requests to: Dr. I. D. Cooke, Department of Physiology. The University of Western Ontario. London, Ontario, Canada, N6A SCI.

Supported in part by the Medical Rescarch Council of Canada ( $P G-1)$ and the Richard and Jean Ivey Fund. London. Ontario. Camada. flexion drift, although there was no change in average movement amplitude. The overall error in position by the end of the non-visually guided trials was greatly in excess of the reported values for passive displacement thresholds in normal subjects. $I t$ is suggested that the data indicate an increased dependence on visual information for control of motor activity in Parkinson's patients.

dérive en flexion, même s'il n'y eul aucun changement dans l'amplitude molenne du mouvement. Lerreur totale sur la position finale dans ces essais non guidés dépassait de beaucoup les valeurs connues pour les seuils de déplacement passif chez les sujets normaux. Il est suggéré que ces résultats indiquent une dépendance accrue sur l'information visuelle pour le contrôle de l'activité motrice dans la maladie de Parkinson.

Purdon Martin (1967) observed that patients akinetic with Parkinson's disease could perform motor activity with relative ease upon presentation of appropriate visual inputs. For example, patients unable to walk over a plain surface walked over the same surface if a series of lines were drawn at right angles to their direction of motion. Such an apparent reliance on visual cues for successful performance of motor activity has recently been observed in monkeys with lesions of the globus pallidus (Hore et al., 1977). In this study performance of forelimb movements was grossly impaired during reversible cooling of the globus pallidus, if the animal had no visual feedback of his arm position. We describe here experiments on patients with Parkinson's disease, indicating a similar increased dependence on visual guidance in the performance of arm movements. The present experiments have been presented in abstract (Cooke et al., 1977).

The data to be presented are representative of the data obtained from three patients with Parkinson's disease and three age-matched normal control subjects. Each of the patients was assessed at a level of Stage III disability on the scale of Hoehn and Yahr (1967). The patient was a 65 year old man in whom the diagnosis of Parkinson's disease had been made in 1977. He showed normal mentation; reduction in facial expression, eye blink, and associated movements; cogwheel rigidity of the neck and arms. The left side was more affected than the right and a resting tremor of the left hand was present. He was not on medication at the time of diagnosis or experimentation.

During the experiment the subject was seated comfortably, grasping a manipulandum handle (Thomas et al., 1976), with his arm held horizontally and supported at the elbow. The handle was connected to a light bar pivoted at the subject's elbow. The subject's vision of his operant arm was blocked by a sheet. A continual record of handle (and thus forearm) position was obtained from a precision potentiometer at the handle pivot point. An oscilloscope placed at eye level approximately 1 meter in front of the subject was used to present a visual display of handle position and/or target position. Target settings, visual display etc. were controlled by a programmable analog-digital system (Thomas and Cooke, 1976). Data was recorded on an analog tape recorder (Honeywell 7600) and was digitized either on- or off-line with a PDP$11 / 40$ system using a $200 \mathrm{~Hz}$ effective sampling rate. 
The subject was required to perform two types of tracking movements by superimposing the handle bar on the target bar: (1) step tracking, where the target abruptly switched between two fixed positions every two seconds, and (2) continous tracking, where the target moved at constant velocity (ramp movement) between two fixed positions. The amplitude of target movement for all tests was $32 \mathrm{deg}$ of arc, and the targets were not bounded by mechanical stops. A movement was considered "in target" if the handle was within $6 \mathrm{deg}$ of the target center. The target width was indicated to the subject by the width of the displayed target bar.

Fig. 1 shows examples of the different types of tracking movements made by the patient with Parkinson's disease and by a normal subject. Both subjects were first required to track the target under visual guidance (VISION - left hand columns). After approximately 40 movements, the subject rested briefly. The handle cursor was then removed (NO VISION - right hand columns) and a further 40 movements were recorded without any external cues of forearm position. Both the patient with Parkinson's disease and the normal subject performed well under the "VISION" conditions. During step tracking, the patient with Parkinson's disease showed a tendency for the arm to drift towards flexion while holding in the extension position between movements, this drift being interrupted periodically by a flexion movement. No overall change in limb position resulted during the course of the trial.

This tendency for flexion drift became more apparent if the handle cursor was not visible, i.e. the subject had to rely on proprioceptive information for limb positioning (Fig. 1; "NO VISION"). The patient with Parkinson's disease showed a progressive drift of arm position towards flexion during both step and continous tracking. Such a flexion drift was seen in both arms in all three patients tested.

Fig. 2A shows mean end positions under the various conditions. For the step tracking movements the end position was taken as the mean arm
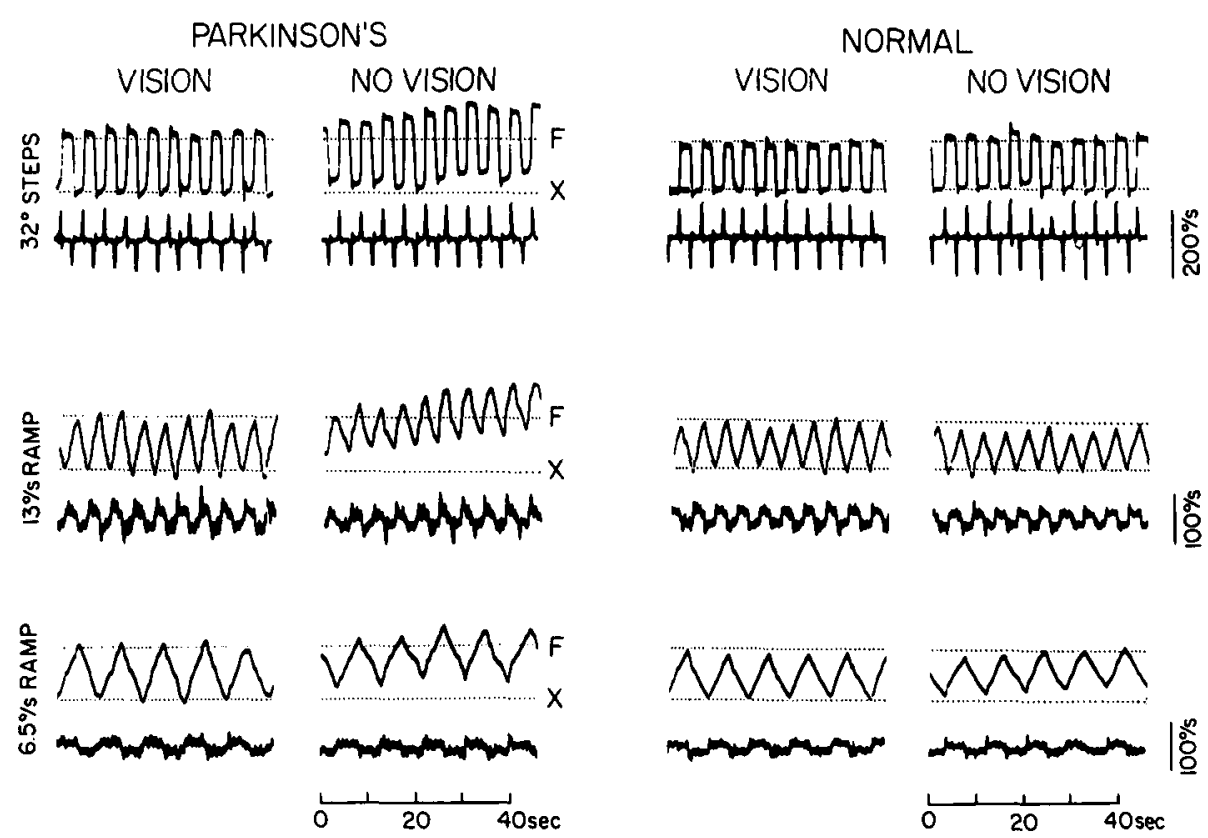

Figure 1 - Each pair of traces indicates handle position (upper trace) and velocity (lower trace) during performance of a tracking task. During the VISION trials both handle and target cursors were visible to the subject; during the NO VISION trials only the target cursor was visible. The traces on the left were obtained from the patient with Parkinson's disease (left arm) and those on the right from the age-matched control (right arm). As indicated, an upward deflection of the position trace indicates a flexion movement. The horizontal dotted lines indicate the target centers for the step tracking trials and the maximum target movement for the ramp tracking trials. The distance between the dotted lines was $32 \mathrm{deg}$ in each case. (AG200477L, WS181077R)

position during holding between movements; for the continuous ( $\mathrm{ramp}$ ) tracking movements it was taken as the arm position when movement direction was reversed. As was indicated in Fig. 1, the patient with Parkinson's disease showed an overall flexion drift when visual information about arm position was not given (NO VISION). Since the plotted points represent the mean positions over the course of the tests, the actual drift was greater than indicated in Fig. $2 \mathrm{~A}$. The variability of arm positioning is indicated by the standard deviation bars. In contrast, the normal subject showed variably a flexion, an extension, or no drift.

The increased variability in arm positioning during the NO VISION trials with the patient with Parkinson's disease was not associated with any overall change in movement amplitude (Fig. 2A). Nor, as may be seen from the velocity records in Fig. 1 and in more detail in Fig. 2B, was there any marked change in the magnitude of the
Parkinson's tremor during the "NO VISION" trials.

The present experiments thus reflect, in humans, the increased dependence on visual information observed in monkeys making accurate arm movements during basal ganglia dysfunction (Hore et al., 1977). In the present study, the subject with Parkinson's disease was unable to accurately maintain proper arm positioning in the absence of visual information about arm position. As the forearm was fully supported this cannot be attributed to loss of control of postural reflexes as was suggested by Martin (1967) in explanation of some of his observations.

In the examples shown in Fig. 1, the overall arm position was $10-20 \mathrm{deg}$ in error by the end of the NO VISION trial. The rate of drift was about 0.3$0.5 \mathrm{deg} / \mathrm{sec}$. At comparable angular velocities, normal subjects have been shown to detect passive angular displacements of less than $1 \mathrm{deg}$ about the elbow (Laidlaw and Hamilton, 


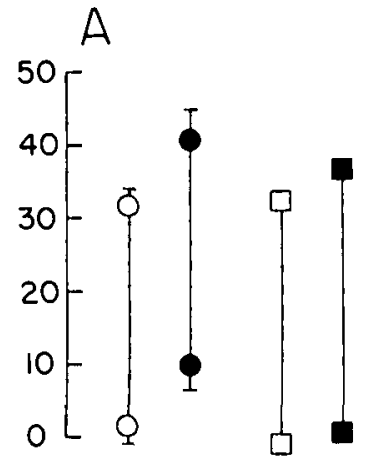

$32^{\circ}$ STEPS
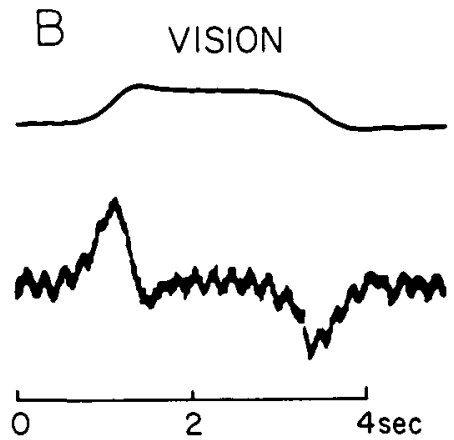

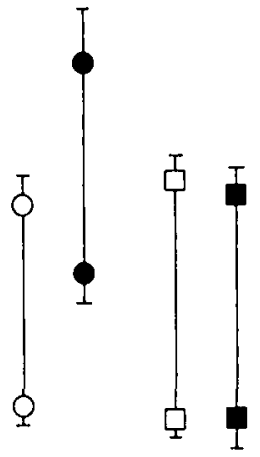

$13 \%$ RAMP

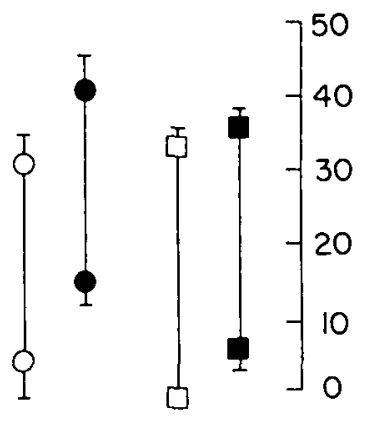

$6.5 \%$ RAMP

from some deficit in proprioceptive mechanisms. Whether the flexion drift seen in the patient with Parkinson's disease may be equated with a passive displacement is uncertain. The former must arise from activity within the central nervous system and, as such, may not necessarily engage proprioceptive mechanisms in the same way or to the same extent as do externally applied displacements.

\section{REFERENCES}

COOKE, J. D., BROOKS, V. B., BROWN, J. and LUCIER, G. (1977). Impaired awareness of arm position in Parkinson patients in the absence of visual feedback. Proc. Soc. Neurosci. Abstr. Vol. III. p. 270.

HOEHN, M. M. and YAHR, M. D. (1967). Parkinsonism: onset, progression and mortality. Neurology 17, 427-442.

HORCH, W., CLARK, F. J. and BURGESS. P. R. (1975). Awareness of knee joint angle under static conditions. J. Neurophysiol. 38, 1436-1447.

HORE, J., MEYER-LOHMANN, J, and BROOKS, V. B. (1977). Basal ganglia cooling disables learned arm movements of monkeys in the absence of visual guidance. Science 195, 584-685.

out (closed symbols) the handle position being displayed. Circles show data obtained from the Parkinson patient and squares from the normal control. Standard deviation bars are shown where greater than the plotted points. The vertical scale represents degrees with the target centers (steps) or maximum target movement (ramps) being at 0 and $32 \mathrm{deg}$. $B$ shows step-tracking movements by the Parkinson patient during VISION and NO VISION trials. The upper trace is handle position and the lower trace velocity. Oscillations at approximately $5 \mathrm{~Hz}$ in the velocity record represent the Parkinson tremor.

1937) and of 3-4 deg about the knee at the much slower velocity of $1 \mathrm{deg} / \mathrm{min}$ (Horch et al., 1975). In the absence of visual information, the patient with Parkinson's disease appeared unable to detect displacements which were well in excess of the threshold for detection of passive displacements in normal humans. Care, however, must be taken in interpreting this as arising
LAIDLAW, R. W. AND HAMILTON. M. A. (1937). The quantitative measurement of apperception of passive movement. Bull. Neurol. Inst. N.Y. 6, 145-153.

MARTIN, J. P. (1967). The Basal Ganglia and Posture. Pitman Medical, London.

THOMAS, J. S. and COOKE, J. D. (1976). A programmable analogdigital system for physiological and behavioural experiments. J. Electrophysiol. Tech. 5, 44-48.

THOMAS, J. S., CROFT, D, and BROOKS, V. B. (1976). A manipulandum for human motor studies. IEEE Trans. Biomed. Eng. 23, 83-84. 